\title{
Significant improvement in nerve conduction, arm length, and upper extremity function after intraoperative electrical stimulation, neurolysis, and biceps tendon lengthening in obstetric brachial plexus patients
}

Rahul K Nath ${ }^{*}$ and Chandra Somasundaram

\begin{abstract}
Background: Progressive loss of extension and concomitant bony deformity of the elbow are results of persistent biceps contracture in obstetric brachial plexus injury (OBPI) patients, if they do not fully recover. This adversely affects the growth and development and functions of the upper extremity.

Patients and method: We have performed biceps tendon lengthening (BTL) using a Z-plasty technique on OBPI patients aged 4 years to adulthood, who had been diagnosed with biceps tendon fixed flexion contractures. Ulnar, radial, and median nerve decompression was also performed at the same sitting. Somatosensory evoked potential (SSEP) monitoring was performed by stimulating the median and ulnar nerves at the wrist and the radial nerve over the dorsum of the hand and recording the peripheral, cervical, and cortical responses.

Seven children with obstetric brachial plexus palsy with an average age of 11 years (8.7-14.2 years) were included in this report. Mean follow-up time was 7.4 months (4-11 months). All the patients in this report had the elbow flexion contractures greater than $30^{\circ}$.

Results: Mean flexion contracture was $35^{\circ}\left(30^{\circ}-45^{\circ}\right)$ preoperatively, which was improved to $0^{\circ}-10^{\circ}$ postoperatively with an average follow-up of 7 (4-11) months. This surgical procedure corrected the elbow flexion contractures, about an average of $25^{\circ}$ and an improved length almost to normal, and improved the upper extremity functions. Neurophysiological data showed significant improvement in conduction of all three nerves tested after neurolysis. Further, median and radial nerve amplitude increase was statistically significant.

Conclusion: Statistically significant improvement in biceps length as well as nerve conduction was observed after the surgery. None of the children in our study lost biceps function, although weakness of the biceps is both a short- and long-term risk associated with biceps lengthening.
\end{abstract}

Keywords: Elbow flexion contracture, Limb length discrepancy, Biceps tendon lengthening, Intraoperative electrical stimulation, Neurolysis, Obstetric brachial plexus injury

\footnotetext{
* Correspondence: nath@drnathmedical.com

Texas Nerve and Paralysis Institute, 6400, Fannin Street, Houston, TX 77030, USA
} 


\section{Background}

Limb length discrepancy and flexion contractures of the elbow are common occurrence, limiting functions of the forearm and hand in permanent obstetric brachial plexus injury (OBPI) patients [1-3]. The flexed elbow posture not only limits upper extremity functions but also may cause pain. The reported prevalence of elbow flexion contracture (EFC) in OBPI patients is ranging widely between $4.6 \%$ and $89.5 \%$ [1,4-6]. EFCs are reported also in children with cerebral palsy involving the upper extremity [7]. Several authors have proposed different etiologies for the occurrence EFC in OBPI.

Hoffer and Phipps (2010) [8] suggested that EFC may be caused by deformation of the elbow joint or imbalance of the muscles or a combination of both [8]. Insufficient power $(<\mathrm{M} 4)$ of the triceps was reported to cause flexion contracture of the elbow [9]. EFC seems to be caused by brachialis muscle pathology [10], and this is not an osseous abnormality. Sheffler et al. [6] also found that majority of the OBPI patients with EFC have normal-appearing elbow radiograph and no radial head dislocation.

Further, they [6] reported the prevalence of contracture increased with increasing age and was found to increase by $4.4 \%$ per year before treatment. OBPI with EFC limited to $15^{\circ}$ to $20^{\circ}$ are usually managed by occupational therapy/long-term night splints. In some patients, the deficit can be severe $\left(30^{\circ}-80^{\circ}\right)$, and this is treated surgically $[1,10-14]$. Standard surgical treatments reported are soft tissue release at the elbow joint in conjunction with lengthening of the biceps, brachialis, and flexor-pronator mass [12,15-19].

We have demonstrated previously that median nerve conduction and shoulder abduction were significantly improved after modified Quad surgery with neuroplasty, internal microneurolysis, and tetanic stimulation of the median nerve in OBPI patients [20]. Further, surgical decompression and neurolysis and tetanic electrical stimulation of the long thoracic nerve significantly improve scapular winging and the associated limitations on shoulder movement [21,22].

Here, we were able to achieve significant improvements in nerve conduction after neurolysis with tetanic stimulation of median, radial, and ulnar nerves in seven OBPI patients.

In addition, we report significant improvement in arm length after BTL surgery and contracture release. In this series of patients, who had $>30^{\circ}$ elbow flexion contracture and significantly shorter arm when compared to the unaffected arm.

\section{Patients and methods}

Seven children with obstetric brachial plexus palsy with an average age of 11 years (8.7-14.2 years) were operated.
Average follow-up time was 7.4 months (4-11 months). All patients had the elbow flexion contractures greater than $30^{\circ}$.

The patients underwent general anesthesia. The arm and hand were prepped and draped in the usual sterile fashion. An incision was created over the volar elbow crease to expose the underlying biceps tendon, the brachialis muscle fascia, and the median and radial nerves. The lacertus fibrosus was identified and released sharply. The biceps tendon was meticulously dissected proximally and distally then sharply released in a $\mathrm{Z}$ fashion, allowing improved passive extension of the elbow joint.

The radial and median nerves were found to be tethered and constricted within the connective tissue of the elbow, probably due to the lack of excursion related to the tendon contractures. Each nerve was externally neurolysed. Internal neurolysis was then performed on each nerve to improve finger and wrist flexion and extension. Similarly, the ulnar nerve was exposed, externally and then internally neurolysed.

The brachialis fascia was exposed, and a series of steplengthening fascial releases were performed to lengthen the brachialis muscle (included in Z-plasty). Partial release of the collateral ligaments was also performed at this point.

\section{Intraoperative tetanic stimulation and neurophysiological evaluation}

Somatosensory evoked potential (SSEP) monitoring was performed by stimulating the median and ulnar nerves at the wrist and the radial nerve over the dorsum of the hand and recording the peripheral, cervical, and cortical responses. Surgical decompression of all three nerves was performed. We evaluated the efficacy of intraoperative electrical stimulation-induced SSEPs in pre- and postdecompression during BTL surgery.

This was a retrospective study of patient charts, which exempted it from the need for IRB approval in the United States. Patients were treated ethically in compliance with the Helsinki declaration. Documented informed consent was obtained for all patients.

\section{Statistical analysis}

Paired Student's t-tests were conducted using Microsoft Excel 2003 with the Analyze-It plug-in (Redmond, WA; and Leeds, UK) to determine if differences between preoperative and postoperative SSEPS was statistically significant. The $\mathrm{p}$ values were two tailed and considered significant if less than or equal to 0.05 .

\section{Results}

Pre- and post-decompression revealed a reduction in stimulus threshold and an increase in amplitude for all three nerves (median, ulnar, and radial) tested after the 

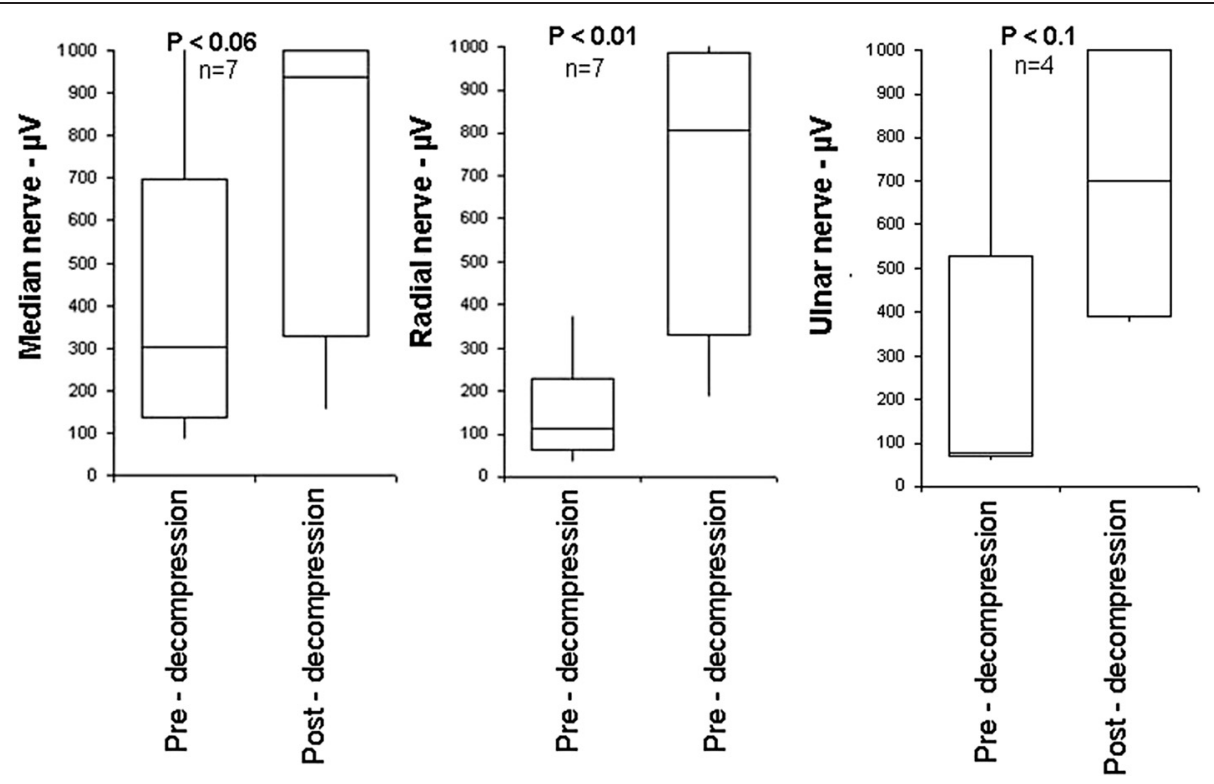

Figure 1 Nerve conduction $(\mu \mathrm{V})$ after intraoperative electrical stimulation and monitoring before and after nerve (median, radial, and ulnar) decompression in OBPI patients. Nerve conduction was improved statistically significantly for both median and radial nerve.

procedure (Figure 1). Amplitude is the response of nerve stimulation that is usually measured in microvolts $(\mu \mathrm{V})$. The stimulus threshold is the minimal stimulation intensity that elicits SSEP. Nerve conduction was improved statistically significantly for both the median and radial nerve. Of the seven patients, ulnar nerve conduction data was available for only four patients, and that might be the reason that ulnar nerve conduction was not statistically significant (Figure 1).

Mean flexion contracture was $35^{\circ}\left(30^{\circ}-45^{\circ}\right)$ preoperatively, which was improved to $0^{\circ}-10^{\circ}$ postoperatively with an average follow-up of 7 (4-11) months (Table 1). We demonstrate here that the BTL surgery corrected the elbow flexion contracture, by an average of $25^{\circ}$ and improved the arm length, and upper extremity functions (Figures 2 and 3). Further, there was no change in muscle strength in five patients and biceps strength improved in two patients after BTL surgery (Table 1).
The mean reduction of the elbow flexion contractures was $25^{\circ}$ in patients with $\mathrm{C} 5-\mathrm{C} 7$, and $30^{\circ}$ in total plexus injury after BTL surgery (Table 1). Our results show that the outcome of this surgery was not significantly different in terms of the severity of the injury in our study group.

\section{Discussion}

We have previously demonstrated that neurolysis with intraoperative tetanic stimulation significantly improved median nerve conduction during modified Quad surgery [20] and an immediate effect on muscle recovery [21,22] in OBPI patients. Modified Quad [23] is a modification of the combination of muscles released and their insert positions to improve upon a previously described operation [24]. In modified Quad procedure, the latissimus dorsi, teres major, subscapularis, and pectoralis muscle contractures are released [23]. BTL surgery was performed

Table 1 Outcome of biceps tendon lengthening in OBPI patients

\begin{tabular}{|c|c|c|c|c|c|c|}
\hline \multirow[t]{2}{*}{ Nerve injury } & \multirow[t]{2}{*}{ Age at surgery } & \multirow[t]{2}{*}{ Strength preop } & \multirow[t]{2}{*}{ Strength postop } & \multicolumn{2}{|c|}{ Elbow flexion contracture } & \multirow[t]{2}{*}{ Follow-up months } \\
\hline & & & & Preop & Postop & \\
\hline Total & 12.9 & $4+$ & $4+$ & $30^{\circ}$ & $10^{\circ}$ & 11 \\
\hline C5-7 & 12.2 & 3.5 & $4+$ & $45^{\circ}$ & $20^{\circ}$ & 4 \\
\hline C5-7 & 9.5 & $4+$ & $4+$ & - & - & 6 \\
\hline C5-7 & 10.7 & $4+$ & $4+$ & $40^{\circ}$ & $0^{\circ}$ & 7 \\
\hline Total & 9.6 & 3.0 & 3.0 & $30^{\circ}$ & $10^{\circ}$ & 7 \\
\hline C5-7 & 8.7 & 4.0 & 4.0 & $30^{\circ}$ & $10^{\circ}$ & 11 \\
\hline C5-6 & 14.2 & 3.5 & 4.0 & $45^{\circ}$ & $10^{\circ}$ & 6 \\
\hline Mean & 11.0 & & & $35^{\circ}$ & $10^{\circ}$ & 7 \\
\hline
\end{tabular}



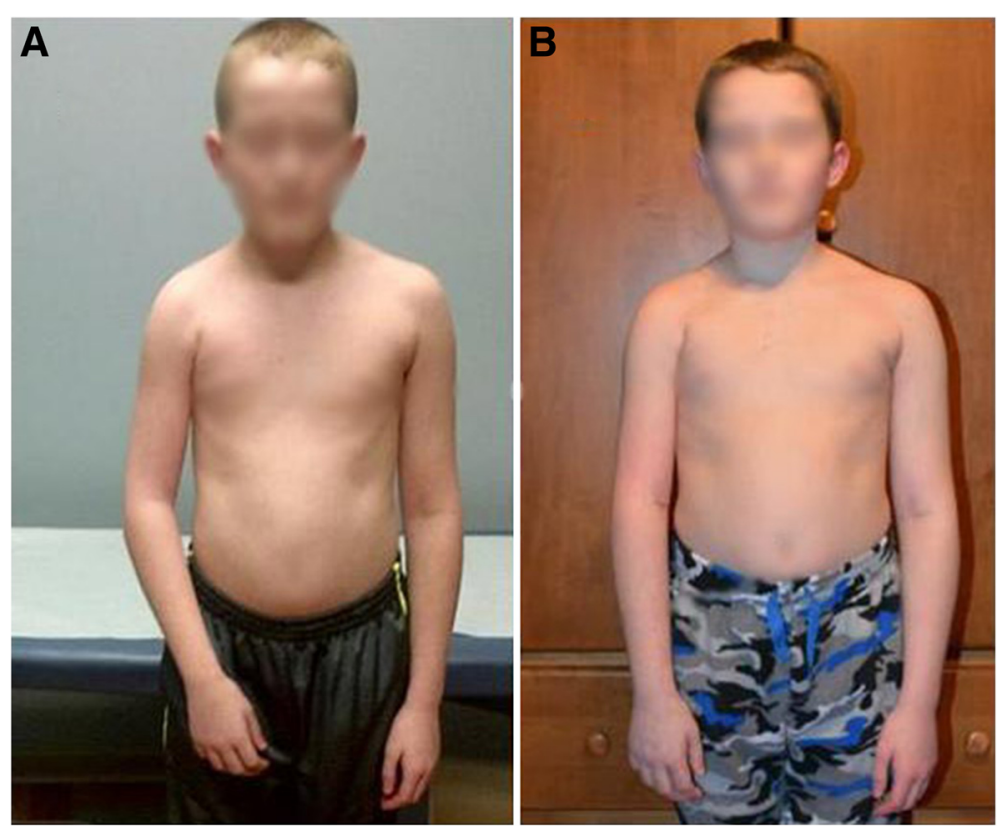

Figure 2 An OBPI male patient with elbow flexion contracture about $40^{\circ}$ and shortening of the right arm before (A) and almost normal after (B) biceps tendon lengthening.

for severe flexion contracture of the elbow. Neurolysis with tetanic stimulation of median, radial, and ulnar nerves was also done to improve this nerve conduction. In this report, intraoperative electrical monitoring confirmed radial, ulnar, and median nerve conduction deficits in these patients prior to decompression and BTL surgery.
Neurolysis with tetanic stimulation of median, radial, and ulnar nerves can have a significant impact on the elbow joint contractures caused by OBPI. Combined with BTL surgery and contracture release, we were able to achieve significant improvements in arm length and function in this series of patients.
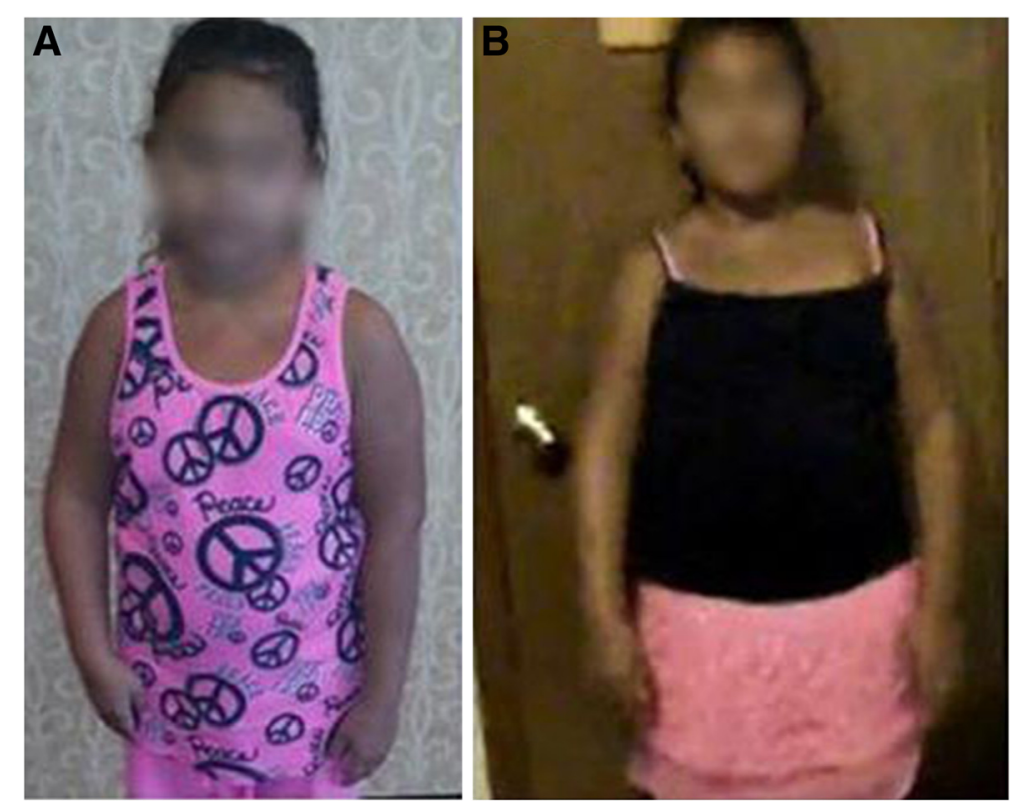

Figure 3 An OBPI female patient with elbow flexion contracture and shortening of the right arm before (A) and almost normal after (B) biceps tendon lengthening. 
Table 2 Patients demographics

\begin{tabular}{|c|c|c|c|c|}
\hline Patient & Nerve injury & Birth history & Previous surgeries & Age at BTL surgery \\
\hline 1 & total & SD, no Horner's syndrome, instruments used, nothing moved & $\pi, M Q$ & 12.9 \\
\hline 2 & C5-7 & SD, no Horner's syndrome, instruments used, nothing moved & $\Pi, M Q$ & 12.2 \\
\hline 3 & C5-7 & SD, no Horner's syndrome, nothing moved & TT, tendon transfer Neurolysis & 9.5 \\
\hline 4 & C5-7 & SD, no Horner's syndrome, fingers moved & $\Pi, M Q, F O$ & 10.7 \\
\hline 5 & Total & SD, no Horner's syndrome, instruments used, nothing moved & $\Pi, M Q$, tendon transfer & 9.6 \\
\hline 6 & C5-7 & SD, no Horner's syndrome, nothing moved & $\Pi, M Q$ & 8.7 \\
\hline 7 & C5-7 & SD, no Horner's syndrome, instruments used, nothing moved & $M Q$, nerve graft neurolysis & 14.2 \\
\hline
\end{tabular}

SD shoulder dystocia, TT triangle tilt, MQ modified Quad.

All patients in our present study documented to have shoulder dystocia. None of them had Horner's syndrome. Five of seven patients were delivered (documented) using either by vacuum or forceps or both. Of all seven patients, one was documented to have finger movement at birth, and no movement for other six patients at birth. All seven patients had the secondary muscle surgery (modified Quad). Six of seven patients also had the bony surgery, triangle tilt in addition to BTL surgery with us. One patient (seventh patient in Table 2) had primary nerve graft at another clinic before presenting to our institution. In addition, two patients had tendon transfer before having treatment with us, and one had forearm osteotomy at another clinic.

Of seven patients, five had C5-C7 upper plexus injury, and two had total brachial plexus injury (Table 2). The mean severity of the contractures in $\mathrm{C} 5-\mathrm{C} 7$ patients was $35^{\circ}\left(30^{\circ}\right.$ to $\left.45^{\circ}\right)$ and $30^{\circ}$ in total plexus injury patients (Table 1). This indicates that the extent of the contractures is not significantly associated with the severity of brachial plexus injury as reported in the literature [6].

The outcome of the surgery and the severity of the contractures in our patients with $\mathrm{C} 5-\mathrm{C} 7$ and total brachial plexus injury were also not significantly different (Table 1) as reported in the literature [6]. In addition, we found that the extent of the contracture was higher $\left(40^{\circ}-45^{\circ}\right)$ in adolescent and teenage $(10.7,12.2$, and 14.2 year old) patients, when compared to the younger children ( $30^{\circ}$ in $8.7,9.5$, and 9.6 year old) except for one patient in our study group (Table 1). Further, elbow position sense is also found impaired in older children and adolescents with OBPI [25].

We demonstrated here that the biceps tendon lengthening corrected the elbow flexion contracture, at about an average of $25^{\circ}$ and improved the arm length significantly, and therefore the upper extremity functions.

\section{Conclusion}

Statistically significant improvement in biceps length as well as nerve conduction was observed after the surgery. None of the children in our report has lost biceps function, although weakness of the biceps is both a short- and long-term risk associated with biceps lengthening. We have not noticed recurrences of nerve compression or elbow flexion. We are currently studying the recovery of the three types of nerve compression but do not have data currently. The limitation of our manuscript is the lack of control group and the comparison with nonoperative treatment of serial casting and nighttime splinting.

\section{Ethical approval statement}

Written informed consent was obtained from all patients for publication and accompanying images. A copy of the written consent is available for review on request.

\section{Competing interests}

The authors declare that they have no competing interests.

\section{Authors' contributions}

RKN conceived of the study, performed all the surgeries, and revised the manuscript. CS participated in the design of the study, performed the statistical analysis, and drafted the manuscript. Both authors read and approved the final manuscript.

Received: 1 December 2014 Accepted: 26 March 2015

Published online: 19 April 2015

\section{References}

1. Ballinger SG, Hoffer MM. Elbow flexion contracture in Erb's palsy. J Child Neurol. 1994;9(2):209-10.

2. Sibinski M, Sherlock DA, Hems TE, Sharma H. Forearm rotational profile in obstetric brachial plexus injury. J Shoulder Elbow Surg. 2007;16(6):784-7.

3. Yam A, Fullilove S, Sinisi M, Fox M. The supination deformity and associated deformities of the upper limb in severe birth lesions of the brachial plexus. J Bone Joint Surg (Br). 2009;91(4):511-6.

4. Kirkos JM, Papadopoulos IA. Late treatment of brachial plexus palsy secondary to birth injuries: rotational osteotomy of the proximal part of the humerus. J Bone Joint Surg (Am). 1998;80(10):1477-83.

5. Waters PM, Bae DS. Effect of tendon transfers and extra-articular soft-tissue balancing on glenohumeral development in brachial plexus birth palsy. J Bone Joint Surg (Am). 2005;87(2):320-5.

6. Sheffler LC, Lattanza L, Hagar Y, Bagley A, James MA. The prevalence, rate of progression, and treatment of elbow flexion contracture in children with brachial plexus birth palsy. J Bone Joint Surg Am. 2012;94(5):403-9.

7. Manske PR, Langewisch KR, Strecker WB, Albrecht MM. Anterior elbow release of spastic elbow flexion deformity in children with cerebral palsy. J Pediatr Orthop. 2001;21(6):772-7.

8. Hoffer MM, Phipps GJ. Surgery about the elbow for brachial palsy. J Pediatr Orthop. 2000;20(6):781-5

9. Ruhmann O, Hierner R. Z-plasty and rerouting of the biceps tendon with interosseous membrane release to restore pronation in paralytic supination posture and contracture of the forearm. Oper Orthop Traumatol. 2009;21 (2):157-69. 
10. Poyhia TH, Koivikko MP, Peltonen Jl, Kirjavainen MO, Lamminen AE, Nietosvaara AY. Muscle changes in brachial plexus birth injury with elbow flexion contracture: an MRI study. Pediatr Radiol. 2007;37(2):173-9.

11. Sheffler LC, Lattanza L, Sison-Williamson M, James MA. Biceps brachii long head overactivity associated with elbow flexion contracture in brachial plexus birth palsy. J Bone Joint Surg Am. 2012;94(4):289-97.

12. Haerle M, Gilbert A. Management of complete obstetric brachial plexus lesions. J Pediatr Orthop. 2004;24(2):194-200.

13. Ho ES, Roy T, Stephens D, Clarke HM. Serial casting and splinting of elbow contractures in children with obstetric brachial plexus palsy. J Hand Surg Am. 2010;35(1):84-91.

14. Morrey BF, An KN, Stormont TJ. Force transmission through the radial head. J Bone Joint Surg Am. 1988;70(2):250-6.

15. Williams BG, Sotereanos DG, Baratz ME, Jarrett CD, Venouziou Al, Miller MC The contracted elbow: is ulnar nerve release necessary? J Shoulder Elbow Surg. 2012;21(12):1632-6.

16. Sebastin SJ, Chung KC. Pathogenesis and management of deformities of the elbow, wrist, and hand in late neonatal brachial plexus palsy. J Pediatr Rehabil Med. 2011;4(2):119-30.

17. Price AE, Grossman JA. A management approach for secondary shoulder and forearm deformities following obstetrical brachial plexus injury. Hand Clin. 1995:11:607-17.

18. Price A, Tidwell M, Grossman JA. Improving shoulder and elbow function in children with Erb's palsy. Semin Pediatr Neurol. 2000;7:44-51.

19. Morrey BF, Askew LJ, Chao EY. A biomechanical study of normal functional elbow motion. J Bone Joint Surg Am. 1981;63(6):872-7.

20. Nath RK, Kumar N, Somasundaram C. Modified Quad surgery significantly improves the median nerve conduction and functional outcomes in obstetric brachial plexus nerve injury. Anals of Surgical Innovation and Research. 2013;7:5

21. Nath RK, Melcher S. Rapid recovery of serratus anterior muscle function after microneurolysis of long thoracic nerve injury. J Brachial Plex PeripherNerve Inj. 2007;2:4

22. Nath RK, Lyons AB, Bietz G. Microneurolysis and decompression of long thoracic nerve injury are effective in reversing scapular winging: long-term results in 50 cases. BMC Musculoskelet Disord. 2007;8:25.

23. Nath RK, Paizi M. Improvement in abduction of the shoulder after reconstructive soft-tissue procedures in obstetric brachial plexus palsy. J Bone Joint Surg Br. 2007;89:620-6.

24. Narakas AO. Muscle transpositions in the shoulder and upper arm for sequelae of brachial plexus palsy. Clin Neurol Neurosurg. 1993;95(Suppl):S89-91.

25. Brown SH, Noble BC, Yang LJ, Nelson VS. Deficits in elbow position sense in neonatal brachial plexus palsy. Pediatr Neurol. 2013;49(5):324-8.

\section{Submit your next manuscript to BioMed Central and take full advantage of:}

- Convenient online submission

- Thorough peer review

- No space constraints or color figure charges

- Immediate publication on acceptance

- Inclusion in PubMed, CAS, Scopus and Google Scholar

- Research which is freely available for redistribution

Submit your manuscript at www.biomedcentral.com/submit 